Article

\title{
Susceptibility of Staphylococcus aureus Clinical Isolates to Propolis Extract Alone or in Combination with Antimicrobial Drugs
}

Robert D. Wojtyczka ${ }^{1}$, Arkadiusz Dziedzic ${ }^{2}$, Danuta Idzik ${ }^{1}$, Małgorzata Kępa ${ }^{1}$, Robert Kubina ${ }^{3}$, Agata Kabala-Dzik ${ }^{3}$, Joanna Smoleń-Dzirba ${ }^{1}$, Jerzy Stojko ${ }^{4}$, Mieczysław Sajewicz ${ }^{5}$ and Tomasz J. Wąsik ${ }^{1} *$

1 Department and Institute of Microbiology and Virology, School of Pharmacy and Division of Laboratory Medicine in Sosnowiec, Medical University of Silesia, ul. Jagiellońska 4, 41-200 Sosnowiec, Katowice, Poland; E-Mails: rwojtyczka@sum.edu.pl (R.D.W.); didzik@sum.edu.pl (D.I.); mkepa@ sum.edu.pl (M.K.); jsmolen@sum.edu.pl (J.S.-D.)

2 Department of Conservative Dentistry with Endodontics, Medical University of Silesia, Pl. Akademicki 17, 41-902 Bytom, Katowice, Poland; E-Mail: adziedzic@ sum.edu.pl

3 Department and Institute of Pathology, Medical University of Silesia, ul. Ostrogórska 30, 41-200 Sosnowiec, Katowice, Poland; E-Mails: rkubina@sum.edu.pl (R.K.); adzik@sum.edu.pl (A.K.-D.)

4 Department Bioanalysis and Environmental Studies, School of Pharmacy and Division of Laboratory Medicine in Sosnowiec, Medical University of Silesia, ul. Kasztanowa 3A, 41-200 Sosnowiec, Katowice, Poland; E-Mail: jstojko@sum.edu.pl

5 Institute of Chemistry, University of Silesia, ul. Szkolna 9, 40-006 Katowice, Poland; E-Mail: mieczyslaw.sajewicz@us.edu.pl

* Author to whom correspondence should be addressed; E-Mail: twasik@ sum.edu.pl; Tel.: +48-32-364-1620; Fax: +48-32-364-0000.

Received: 6 June 2013; in revised form: 23 July 2013 / Accepted: 26 July 2013 / Published: 12 August 2013

Abstract: The objective of this study was to assess in vitro the antimicrobial activity of ethanolic extract of Polish propolis (EEPP) against methicillin-sensitive Staphylococcus aureus (MSSA) and methicillin-resistant Staphylococcus aureus (MRSA) clinical isolates. The combined effect of EEPP and 10 selected antistaphylococcal drugs on $S$. aureus clinical cultures was also investigated. EEPP composition was analyzed by a High Performance Liquid Chromatography (HPLC) method. The flavonoid compounds identified in Polish Propolis included flavones, flavonones, flavonolols, flavonols and phenolic acids. EEPP displayed varying effectiveness against twelve $S$. aureus strains, with 
minimal inhibitory concentration (MIC) within the range from 0.39 to $0.78 \mathrm{mg} / \mathrm{mL}$, determined by broth microdilution method. The average MIC was $0.54 \pm 0.22 \mathrm{mg} / \mathrm{mL}$, while calculated $\mathrm{MIC}_{50}$ and $\mathrm{MIC}_{90}$ were $0.39 \mathrm{mg} / \mathrm{mL}$ and $0.78 \mathrm{mg} / \mathrm{mL}$, respectively. The minimum bactericidal concentration (MBC) of the EEPP ranged from 0.78 to $3.13 \mathrm{mg} / \mathrm{mL}$. The in vitro combined effect of EEPP and 10 antibacterial drugs was investigated using disk diffusion method-based assay. Addition of EEPP to cefoxitin (FOX), clindamycin (DA), tetracycline (TE), tobramycin (TOB), linezolid (LIN), trimethoprim+sulfamethoxazole $(\mathrm{SXT})$, penicillin $(\mathrm{P})$, erythromycin $(\mathrm{E})$ regimen, yielded stronger, cumulative antimicrobial effect, against all tested $S$. aureus strains than EEPP and chemotherapeutics alone. In the case of ciprofloxacin (CIP) and chloramphenicol (C) no synergism with EEPP was observed.

Keywords: methicillin-resistant S. aureus (MRSA); methicillin-sensitive S. aureus (MSSA); ethanolic extract of Polish propolis (EEPP)

\section{Introduction}

The coagulase-positive $S$. aureus is a major pathogen responsible for various community-onset and hospital acquired infections. It causes skin and soft tissues infections, surgical site infections, bone infections pneumonia, bacteremia, endocarditis and joints infections [1-3]. The nasal carriage of S. aureus in healthy adults was reported to be around $20 \%-30 \%$ of the population. Colonization clearly increases the risk for subsequent infection [4,5]. At present the $\beta$-lactam antibiotics are the preferred drugs against $S$. aureus infections. Antibiotic resistant staphylococci strains are a major public health concern since the bacteria can easily circulate in the environment. $S$. aureus has developed resistance to the $\beta$-lactam antibiotics due to synthesis of chromosomal or plasmid encoded $\beta$-lactamases [4-6]. In comparison with methicillin-sensitive Staphylococcus aureus (MSSA), methicillin-resistant Staphylococcus aureus (MRSA) strains pose more problems, since invasive MRSA infections are associated with greater costs and limited treatment options [7].

Propolis (bee glue) is a natural resinous substance produced by honeybees (Apis mellifera) from plants' buds and exudates, modified by addition of bees' salivary secretions and wax $[8,9]$. It has been the subject of scientific interest for its diverse range of biological properties, including anti-inflammatory [10,11], immunomodulatory [12,13], anti-carcinogenic [14,15], antioxidant [16,17], radioprotective [18], antiviral [19], and antifungal [20] effects. What is more, the antibacterial activity of propolis has been confirmed in many studies [19,21-25]. The wide spectrum of biological activities of propolis has been attributed to its complex chemical composition, which is however, dependent on the plant species from which it is harvested, and may be influenced by the geographical and climatic factors, as well as the type of foraging honeybee [8,24-27]. In addition, it has been demonstrated that there were some differences in the antibacterial activity of propolis extracts depending on the collection region [26] and the races of honeybee [21]. Nevertheless, due to the complex and multidirectional mechanism of action of all types of propolis on bacterial cell $[28,29]$, development of resistance to this substance is complicated and unlikely. For this reason, in the light of a rapid and widespread emergence of bacterial strains resistant to classic chemotherapeutics [30], beneficial, 
antimicrobial properties of propolis may be helpful in treatment of current bacterial infections. Studies on chemical composition of propolis from different geographical regions showed characteristic classes of compounds which correlated with selected plant sources. The most frequent techniques currently used for chemical composition analysis of propolis are spectrophotometric methods (UV-VIS, HP-TLC), high performance liquid chromatography (HPLC-DAD) coupled with different detectors, and gas chromatography-mass spectrometry (GC-MS) [31-33].

Many reports showed that $S$. aureus appears to be naturally susceptible to propolis [34]. Recent studies [8] revealed that propolis exerts synergistic effects with antibiotics, acting on the bacterial wall structure and ribosomes function, but it does not seem to interact with antibiotics acting on DNA or folic acid biosynthesis [35]. The mechanism of propolis antibacterial activity seems to be linked to some of its components. The potent bacteriostatic and bactericidal effects of propolis can be associated with their combined action manifested by inhibition of protein synthesis and bacterial growth by preventing cell division [36,37].

Particularly, the notion of using a combination of propolis and antibiotics to augment antibacterial therapy appears promising [34,38-43]. Some in vitro studies indicated evident synergism between propolis and antibiotics with a clear decrease of minimal inhibitory concentrations (MICs) for tested drugs [28,39], while in others this effect was less obvious [42], or not observed [41]. The results of the research carried out by Fernandes Junior et al., demonstrated the synergism between EEP and those antibacterial agents that interfere with bacterial protein synthesis, e.g. chloramphenicol, gentamicin, netilmicin, tetracycline and clindamycin [38]. The antibacterial activity of propolis, together with its potential to enhance the antimicrobials efficacy due to possible synergistic interactions, could be especially advantageous in the treatment of $S$. aureus infections, which currently represent a significant burden on healthcare systems across the world [44].

Thus, since there is a great and still growing need for the enhancement of therapy of infections caused by different $S$. aureus strains, the objective of this study was to assess the in vitro antimicrobial activity of ethanolic extract of Polish propolis (EEPP) against MSSA and MRSA clinical isolates. To make sure that bacterial strains were identified unambiguously the Polymerase Chain Reaction-Restriction Fragment Length Polymorphism (PCR-RFLP) technique with XapI and Bsp143I restriction enzymes was applied. The investigation of the activity of the EEPP alone and in combination with selected antistaphylococcal drugs on MSSA and MRSA cultures was also evaluated.

\section{Results and Discussion}

Quantitative analyses of ethanolic extracts of propolis are presented in Figure 1. Figure 1 represents a typical HPLC chromatogram of EEPP. Qualitative and quantitative analysis of selected flavonoids and phenolic acids was carried out, with the identification of pinocembrin, kaempferol, galangin, chrysin, apigenin, quercetin, gallic acid, ferullic acid, caffeic acid, caffeic acid phenethyl ester, $p$-coumaric acid and cinnamic acid. The flavonoid compounds identified in this study included flavones, flavanones, flavanolols, flavonols and chalcons. Most flavonoid compounds displayed the typical pattern of "poplar" propolis. Several studies showed that flavonoids have antimicrobial, anticancer, antioxidant action. It is known that the amount of phenolic and flavonoid constituents varies widely according to propolis types and seasonal factors. The HPLC analysis showed that flavonoid compounds of Polish propolis are similar 
to other ethanolic extracts of propolis, especially of European origin $[17,24,26,28,36]$. We made the conclusion that Polish propolis possesses significant amounts of biologically active compounds belonging to the classes of phenolic acids, and different classes of flavonoids (flavones/flavonols, flavanones/dihydroflavonols or other phenols) and can be subjected to other 'validated' methods for European poplar type propolis. Therefore, the multi-directional interactions among the various chemical compounds in propolis seem to be the essential biological activities when considering its antibacterial effects against pathogens.

Figure 1. HPLC chromatogram of propolis ethanolic extract from Poland. 1-Cinnamic acid (Rt-5.20); 2-p-Coumaric acid (Rt-5.69); 3-Ferulic acid (Rt-6.23); 4-Gallic acid (Rt-6.98); 5-Caffeic acid (Rt-7.36); 6-Caffeic acid phenethyl ester (Rt-8.63); 7-Pinobaksin (Rt-8.97); 8-Kaempferol (Rt-9.34); 9-Apigenin (Rt-10.40); 10-Pinocembrin (Rt-10.92); 11-Quercetin (Rt-13.19); 12-Chrysin (Rt-13.93); 13-Galangin (Rt-14.72); 14-Acecetin (Rt-17.46); 15-Kampferide (Rt-21.67); Rt- retention time (min).

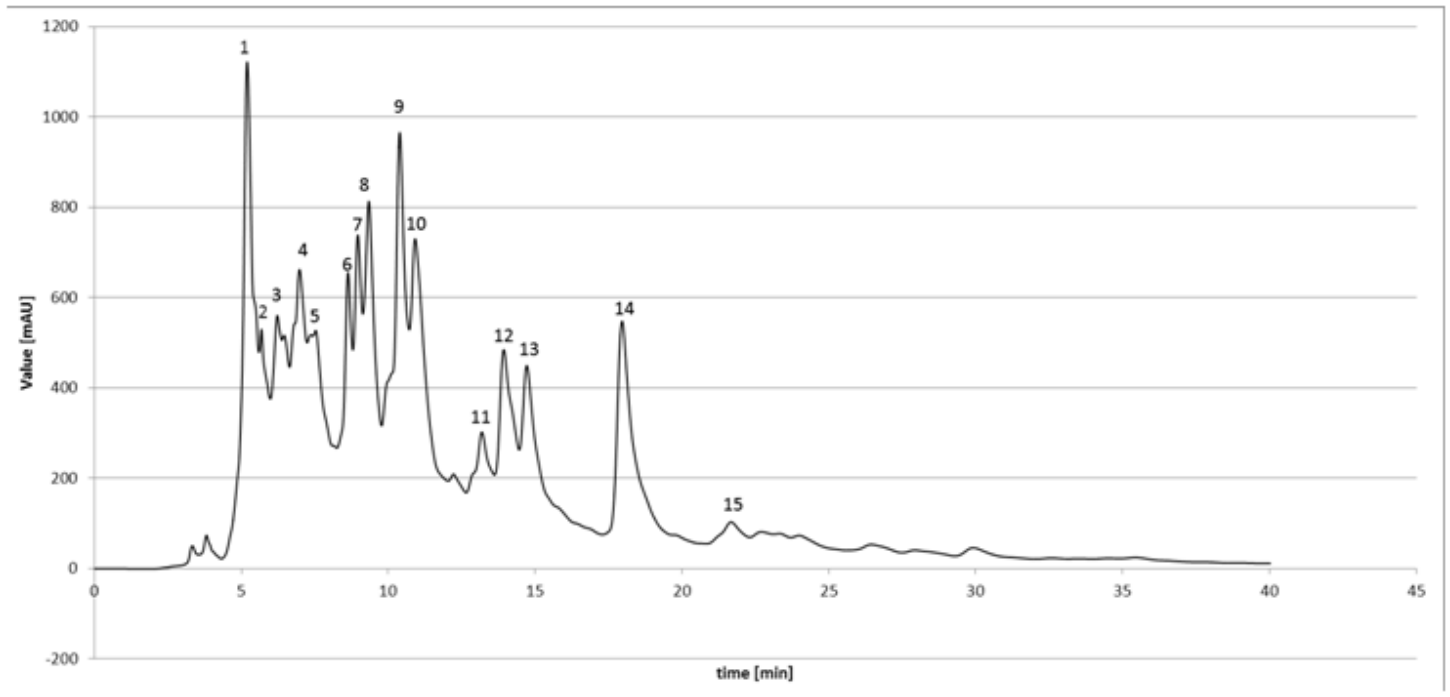

According to the standard and molecular method 10 clinical isolates were classified as belonging to the Staphylococcus aureus species (Table 1, Figure 2).

Figure 2. Identification of mecA gene fragment (533 bp). W1-S. aureus MSSA ATCC 25923; W2-S. aureus MRSA ATCC 43300; 1-10 S. aureus clinical isolates; M-100-1000 bp marker, (+) positive control, (-) negative control.

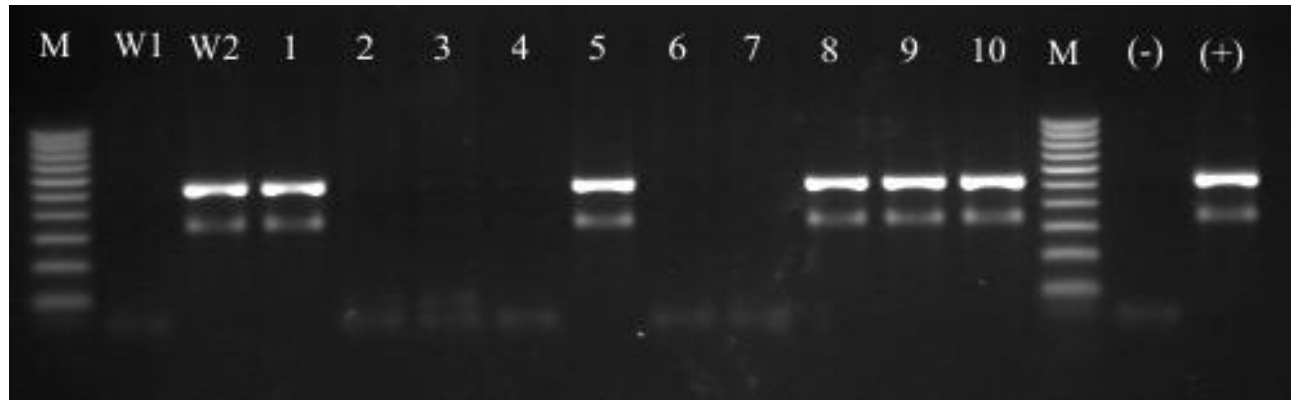


Catalase positive, coagulase positive and mannitol fermenting staphylococcal strains were identified biochemically by the API STAPH system. The molecular species identification of coagulase-positive staphylococci by PCR-RFLP technique with XapI and Bsp143I restriction enzymes confirmed that all isolates were $S$. aureus strains.

Table 1. The phenotypic (Cefoxitin test) and genetic (PCR mecA gene) assessment of S. aureus strains susceptibility to methicillin.

\begin{tabular}{lccc}
\hline \multicolumn{1}{c}{ Strain } & Cefoxitin test & mecA & MSSA/MRSA \\
\hline S. aureus 1 & $17 \mathrm{~mm}$ & + & MRSA \\
S. aureus 2 & $34 \mathrm{~mm}$ & - & MSSA \\
S. aureus 3 & $34 \mathrm{~mm}$ & - & MSSA \\
S. aureus 4 & $33 \mathrm{~mm}$ & - & MSSA \\
S. aureus 5 & $22 \mathrm{~mm}$ & + & MRSA \\
S. aureus 6 & $34 \mathrm{~mm}$ & - & MSSA \\
S. aureus 7 & $34 \mathrm{~mm}$ & - & MSSA \\
S. aureus 8 & $13 \mathrm{~mm}$ & + & MRSA \\
S. aureus 9 & $16 \mathrm{~mm}$ & + & MRSA \\
S. aureus 10 & $14 \mathrm{~mm}$ & + & MRSA \\
S. aureus $\mathrm{W}^{1}$ & $35 \mathrm{~mm}$ & - & MSSA \\
S. aureus $\mathrm{W}^{2}$ & $21 \mathrm{~mm}$ & + & MRSA \\
\hline \multicolumn{1}{c}{$\mathrm{W}^{1}:$ S. aureus MSSA ATCC 25923; $\mathrm{W}^{2}:$ S. aureus MRSA ATCC 43300. }
\end{tabular}

The broth microdilution method was used to determine the MICs of the EEPP against 12 S. aureus strains. EEPP displayed varying degree of activity against $S$. aureus with MIC values ranging from $0.39 \mathrm{mg} / \mathrm{mL}$ to $0.78 \mathrm{mg} / \mathrm{mL}$ (Tables 2 and 3). The average MIC was $0.54 \pm 0.22 \mathrm{mg} / \mathrm{mL}, \mathrm{MIC}_{50}$ and $\mathrm{MIC}_{90}$ values were $0.39 \mathrm{mg} / \mathrm{mL}$ and $0.78 \mathrm{mg} / \mathrm{mL}$, respectively. The MBC values of the EEPP ranged from $0.78 \mathrm{mg} / \mathrm{mL}$ to $3.13 \mathrm{mg} / \mathrm{mL}$.

Table 2. Susceptibility of $S$. aureus MSSA strains to EEPP (MIC and MBC values in $\mathrm{mg} / \mathrm{mL}$ ).

\begin{tabular}{ccccccc}
\hline Strain & $\mathbf{2}$ & $\mathbf{3}$ & $\mathbf{4}$ & $\mathbf{6}$ & $\mathbf{7}$ & $\mathbf{W}^{\mathbf{1}}$ \\
\hline MIC EEPP $(\mathrm{mg} / \mathrm{mL})$ & 0.39 & 0.39 & 0.78 & 0.78 & 0.78 & 0.39 \\
MBC EEPP $(\mathrm{mg} / \mathrm{mL})$ & 1.56 & 1.56 & 3.13 & 3.13 & 1.56 & 3.13 \\
\hline
\end{tabular}

$\mathrm{W}^{1}$ : S. aureus ATCC 25923.

Table 3. Susceptibility of $S$. aureus MRSA strains to EEPP (MIC and MBC values in $\mathrm{mg} / \mathrm{mL}$ ).

\begin{tabular}{ccccccc}
\hline Strain & $\mathbf{1}$ & $\mathbf{5}$ & $\mathbf{8}$ & $\mathbf{9}$ & $\mathbf{1 0}$ & $\mathbf{W}^{\mathbf{2}}$ \\
\hline MIC EEPP $(\mathrm{mg} / \mathrm{mL})$ & 0.39 & 0.39 & 0.39 & 0.39 & 0.78 & 0.78 \\
MBC EEPP $(\mathrm{mg} / \mathrm{mL})$ & 3.13 & 3.13 & 0.78 & 0.78 & 3.13 & 3.13 \\
\hline
\end{tabular}

$\mathrm{W}^{2}$ : S. aureus MRSA ATCC 43300.

Values of MIC and MBC EEPP against MSSA strains were successively $0.59 \pm 0.21 \mathrm{mg} / \mathrm{mL}$ and $2.5 \pm 0.85 \mathrm{mg} / \mathrm{mL}$. In the case of MRSA strains the MIC and MBC were as follows: $0.52 \pm 0.2 \mathrm{mg} / \mathrm{mL}$ and $2.35 \pm 1.21 \mathrm{mg} / \mathrm{mL}$. 
The in vitro combined effect of EEPP and 10 antibacterial drugs (FOX, DA, E, CIP, TE, P, TOB, LIN, C, SXT) was tested using disk diffusion method-based analysis, and the results are shown in Figure 3. This analysis revealed synergism between EEPP and FOX, DA, TE, TOB, LIN, P, E, and SXT for all tested MSSA and MRSA strains. In the case of CIP and C synergism with EEPP was not observed.

Figure 3. Inhibitory effect of 10 antimicrobial agents alone, and in combination with EEPP on 12 Staphylococcus strains evaluated by disk diffusion method. (A) FOX and FOX+EEPP; (B) DA and DA+EEPP; (C) E and E+EEPP; (D) CIP and CIP+EEPP; (E) TE and TE+EEPP; (F) P and P+EEPP; (G) TOB and TOB+EEPP; (H) LIN and LIN+EEPP; (I) $\mathrm{C}$ and C+EEPP; (J) STX and STX+EEPP. MHA: Mueller-Hinton Agar; MHA with EEPP: MHA plus one-fourth of MIC90 of EEPP; blue bars: diameters of the growth inhibition zones (in $\mathrm{mm}$ ) for antibiotic alone; red bars: diameters of the growth inhibition zones (in $\mathrm{mm}$ ) for combined effect of antibiotics and EEPP; FOX: Cefoxitin; DA: Clindamycin; E: Erythromycin; CIP: Ciprofloxacin; TE: Tetracycline; P: Penicillin; TOB: Tobramycin; LIN: Linezolid; C: Chloramphenicol; STX: Trimethoprim+Sulfamethoxazole; K1: S. aureus ATCC 25923; K2: S. aureus MRSA ATCC 43300; * Wilcoxon Signed-Rank Test, statistical significant level at $p<0.05$.

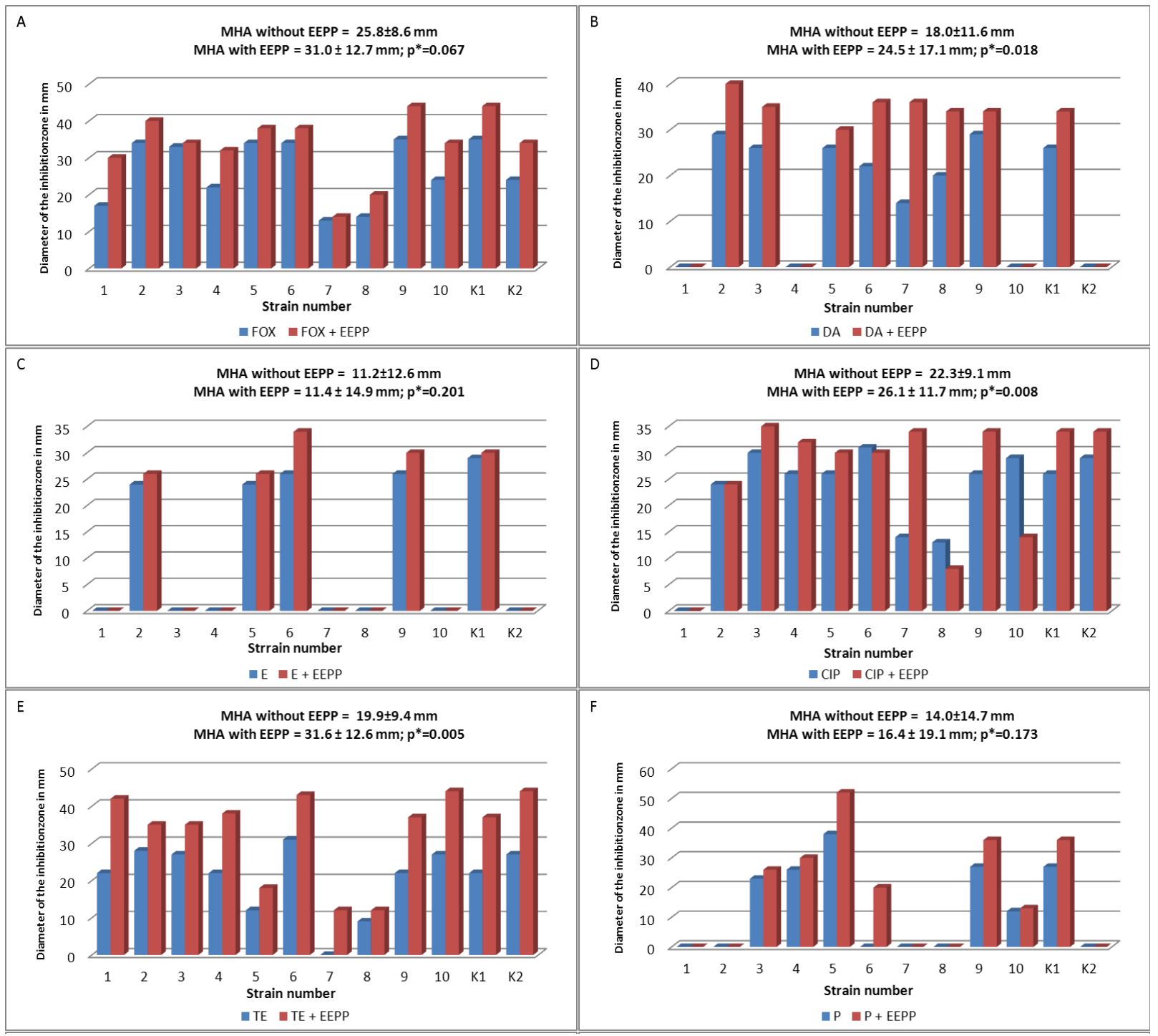


Figure 3. Cont.

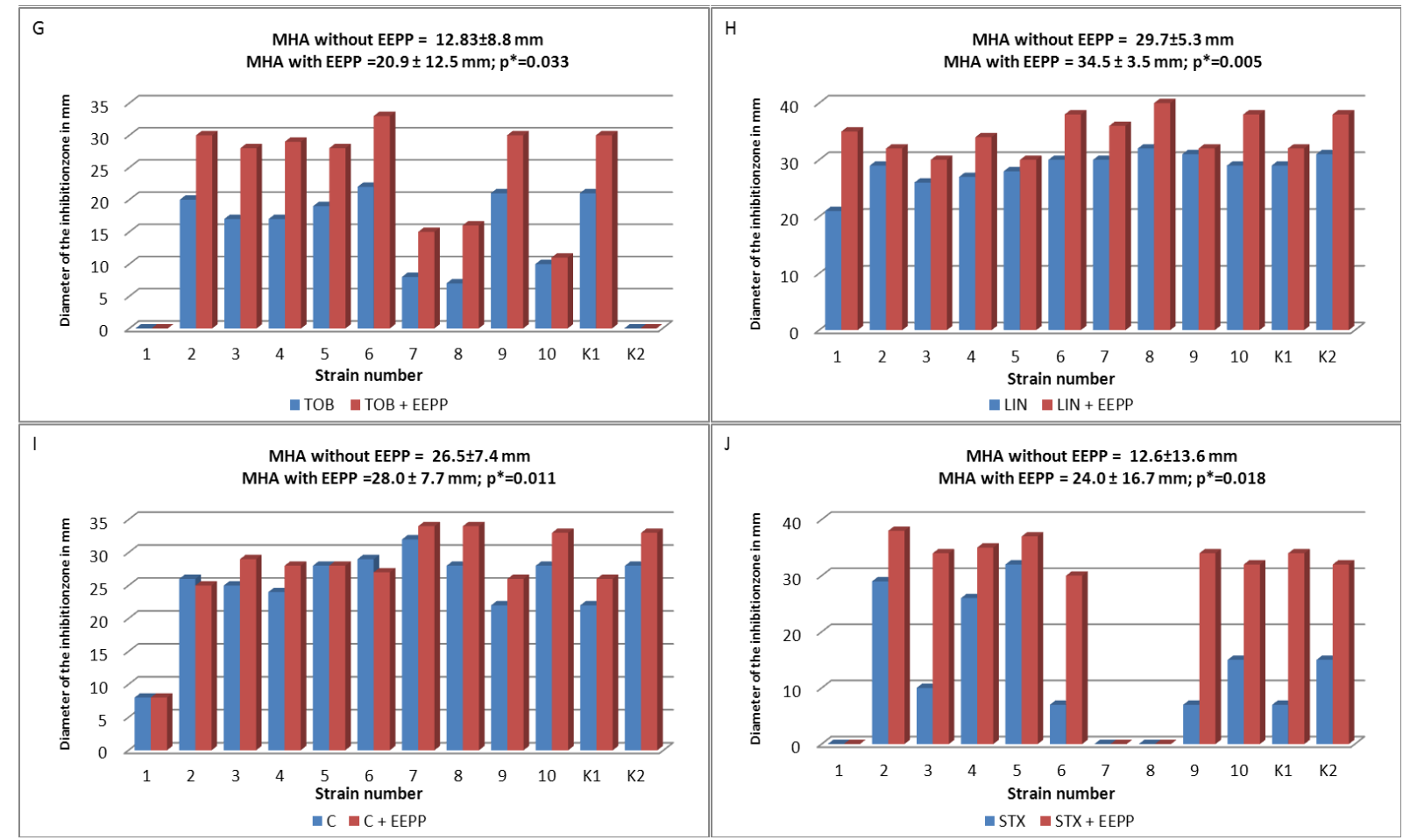

The analysis of bacterial growth after first $6 \mathrm{~h}$ of incubation showed that the growth of all strains in the medium supplemented with EEPP at concentrations ranging from 0.0125 to $0.39 \mathrm{mg} / \mathrm{mL}$ was not inhibited (Figure 4A). After $12 \mathrm{~h}$ of incubation, the growth of all strains was observed in the wells with the same range of EEPP concentrations (Figure 4B). After $24 \mathrm{~h}$ of incubation the growth of all MRSA and MSSA strains was observed at concentrations ranging from 0.0125 to $0.78 \mathrm{mg} / \mathrm{mL}$ (Figure 4C).

Figure 4. Growth of $S$. aureus strains in the presence of different EEPP concentrations. (A) After $6 \mathrm{~h}$ of incubation; (B) After $12 \mathrm{~h}$ of incubation; (C) After $24 \mathrm{~h}$ of incubation; GC: Growth control.

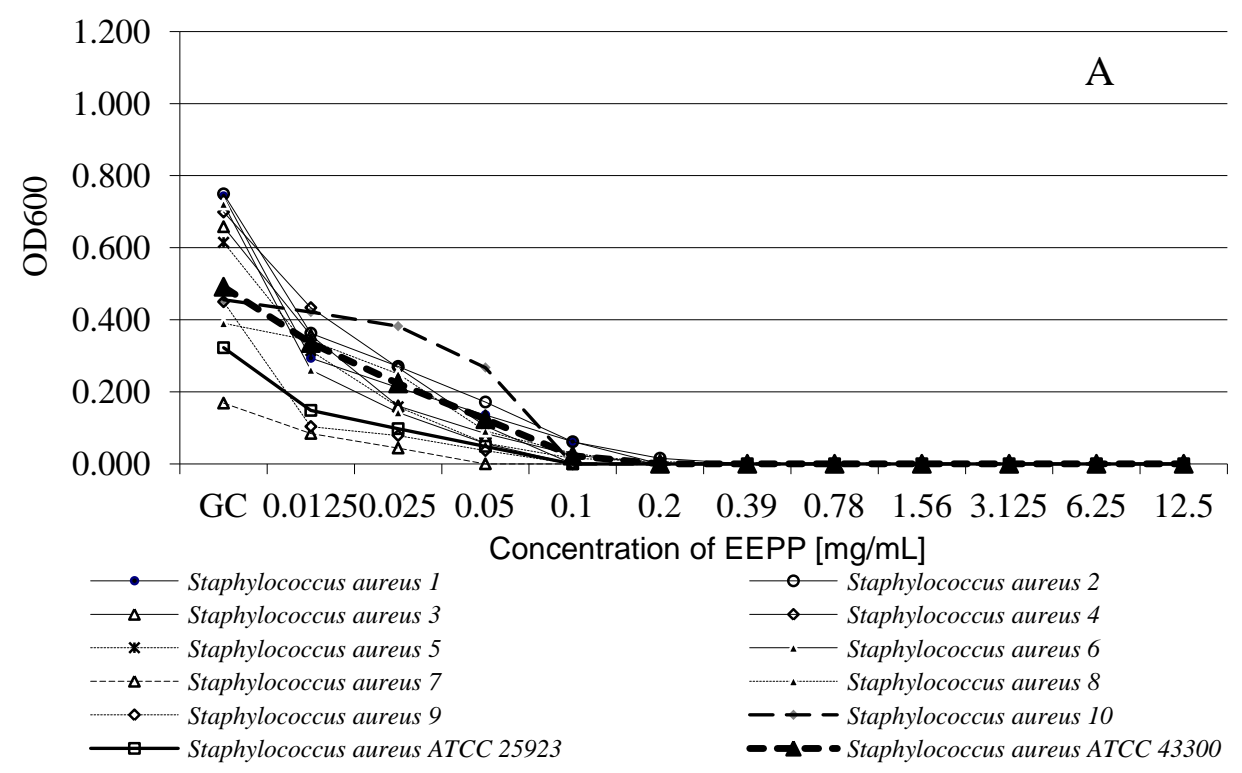


Figure 4. Cont.
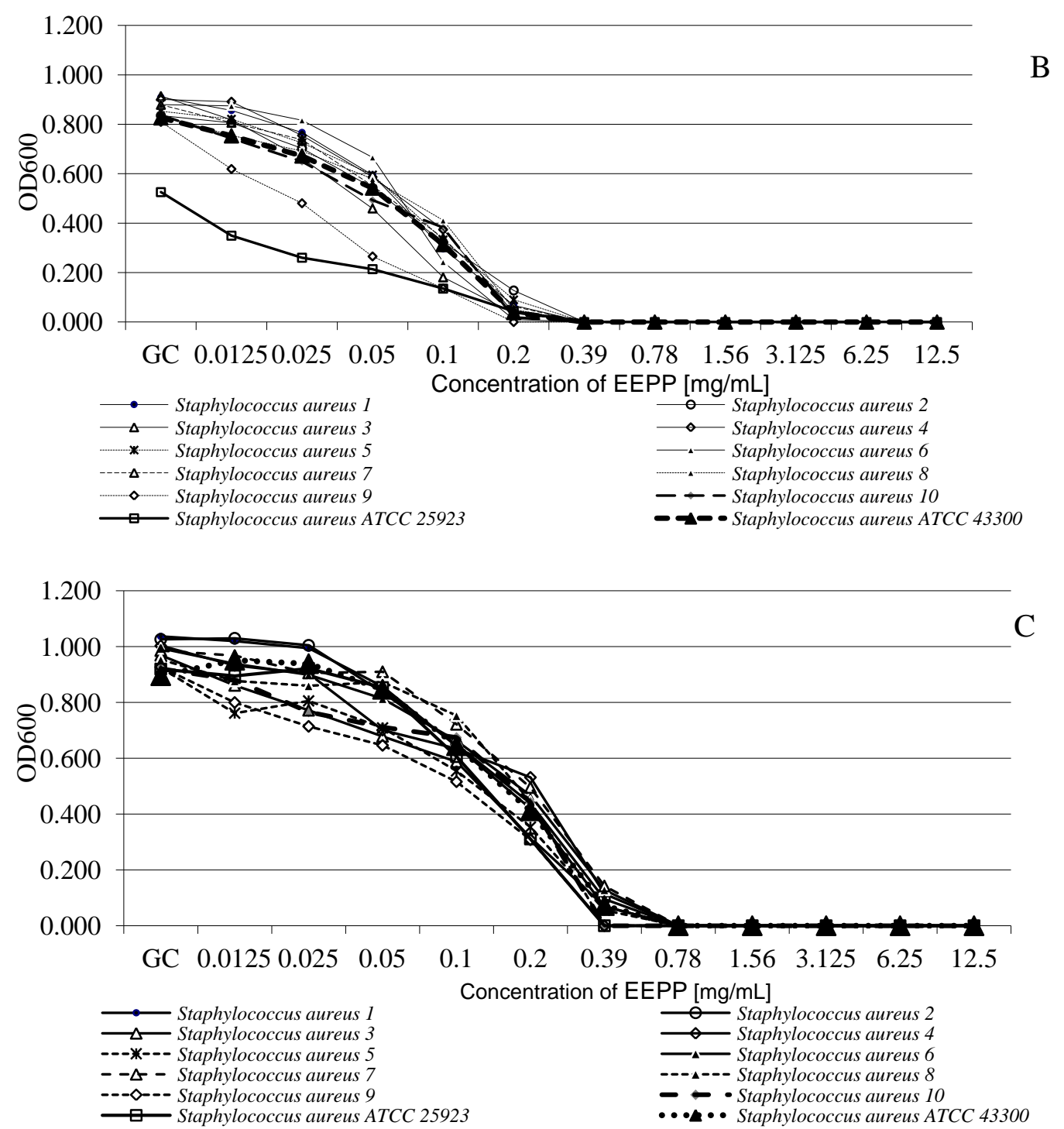

The three-way ANOVA indicated that the growth of all $S$. aureus strains was significantly affected by EEPP concentration $(p<0.001)$ and incubation time $(p<0.001)$. The interaction between these factors was also significant $(p<0.001)$. The EEPP concentration effect $(40.12 \%)$, incubation time $(21.10 \%)$, and interaction between concentration and incubation time (20.23\%) explained most of variance (Table 4).

Table 4. Multivariate analysis of variance by three-way ANOVA of S. aureus strains susceptibility to EEPP

\begin{tabular}{ccccccc}
\hline $\begin{array}{c}\text { Source of } \\
\text { variation }\end{array}$ & df & $\begin{array}{c}\text { Sum of } \\
\text { squares }\end{array}$ & $\begin{array}{c}\text { Mean } \\
\text { squares }\end{array}$ & $\begin{array}{c}\text { Variance } \\
\text { explained (\%) }\end{array}$ & F & $p$ \\
\hline Strain (S) & 11 & 0.67 & 0.06 & 0.71 & 27.2 & $<0.001$ \\
Time (T) & 2 & 19.8 & 9.9 & 21.10 & 4414.6 & $<0.001$ \\
Concentration (C) & 11 & 37.65 & 3.42 & 40.12 & 1526.5 & $<0.001$ \\
S x T & 22 & 1.46 & 0.07 & 1.56 & 29.5 & $<0.001$ \\
S x C & 121 & 6.74 & 0.06 & 7.18 & 24.8 & $<0.001$ \\
T x C & 22 & 18.99 & 0.86 & 20.23 & 384.9 & $<0.001$ \\
SxTxC & 242 & 8.54 & 0.04 & 9.01 & 15.7 & $<0.001$ \\
\hline
\end{tabular}


In this study; MIC EEPP values ranged from 0.39 to $0.78 \mathrm{mg} / \mathrm{mL}$, while $\mathrm{MBC}$ values ranged from 0.78 to $3.13 \mathrm{mg} / \mathrm{mL}$. For MRSA strains, average MIC values were $0.52 \pm 0.2 \mathrm{mg} / \mathrm{mL}$, and for MSSA strains $0.59 \pm 0.21 \mathrm{mg} / \mathrm{mL}$. The MBC average values were similar for MRSA and MSSA strains, and found to be $2.35 \pm 1.21 \mathrm{mg} / \mathrm{mL}$ and $2.35 \pm 0.86 \mathrm{mg} / \mathrm{mL}$, respectively. The $\mathrm{MIC}_{\mathrm{AB}}$ average values were similar for MRSA and MSSA strains, and found to be $0.41 \pm 0.22 \mathrm{mg} / \mathrm{mL}$ and $0.42 \pm 0.31 \mathrm{mg} / \mathrm{mL}$, respectively. The ethanol in EEPP was not responsible for the anti-staphylococcal activity of EEPP when compared to $70 \%$ ethanol control.

It was previously reported that ethanolic extract of propolis showed various inhibitory activities against different microorganisms when tested in vitro [22,26,34,43,45,46] and in vivo [47]. In the study of Takaisi-Kikuni and Schilcher [29], some mechanisms of propolis activity on bacterial growth have been discussed. Havsteem [36] and Oksuz et al. [37] suggested that the specific propolis ingredients inhibit protein synthesis and bacterial growth by preventing cell division, resulting in the formation of pseudo-multicellular bacterial forms. Galangin and caffeic acid from EEP are enzymatic inhibition agents responsible for an inhibition of bacterial growth and proliferation. In addition, some active substances composing propolis may disorganize the cytoplasmic membrane and cell wall, with the effect of a partial bacteriolysis. Flavonoids affect bacterial membrane potential and cause permeability alteration within the inner microorganisms membrane [28].

Numerous studies have shown that the antimicrobial effect of EEP may vary according to the geographic region, as the propolis samples from different locations may exhibit different chemical composition. Seidel et al. [26] presented an evaluation of the antibacterial activity of 40 propolis samples collected from various locations worldwide. The propolis samples from Africa and Asia showed moderate activity, with MICs ranging from 0.0156 to $>0.5 \mathrm{mg} / \mathrm{mL}$ and 0.0078 to $>0.5 \mathrm{mg} / \mathrm{mL}$, respectively. Samples from North and South America and samples collected in Europe displayed similar anti-staphylococcal activity, with the MIC values in the range of 0.125 to $>0.5 \mathrm{mg} / \mathrm{mL}$. Kilic et al. analyzing EEP effect on MRSA strains reported that MIC values of propolis samples from three different regions of Turkey, i.e. Mamak and two Kemaliye locations varied and amounted to $0.018 \pm 0.008,0.162 \pm 0.073$, and $0.101 \pm 0.040 \mathrm{mg} / \mathrm{mL}$, respectively [48]

The results presented by Berretta et al. [49] demonstrated that the MBC of three samples of standardized propolis extract tested against S. aureus ATCC 25923 and S. aureus ATCC 43300 were in the range from 6.96 to $7.02 \mathrm{mg} / \mathrm{mL}$ and 3.48 to $3.51 \mathrm{mg} / \mathrm{mL}$ respectively.

In the present study for the same reference strains the EEPP MBC values were lower $(3.13 \mathrm{mg} / \mathrm{mL})$ showing higher bactericidal activity of Polish propolis' extract. The diverse antimicrobial activity of EEP shown by many authors and in our manuscript can be due to the differences in the origin of propolis, and its qualitative and quantitative composition.

Wojtyczka et al. [25] showed the antistaphylococcal activity of the Polish EEPP against $11 \mathrm{~S}$. epidermidis strains using the broth microdilution method. In this study EEPP displayed varying degrees of activity against CoNS with MIC in the range of $1.56-0.78 \mathrm{mg} / \mathrm{mL}$. The average MIC was $1.13 \pm 0.39 \mathrm{mg} / \mathrm{mL}$ while calculated $\mathrm{MIC}_{50}$ and $\mathrm{MIC}_{90}$ were $0.78 \mathrm{mg} / \mathrm{mL}$ and $1.56 \mathrm{mg} / \mathrm{mL}$, respectively.

Investigated hospital-acquired clinical isolates revealed varying susceptibility to antibiotics. Apart from the common resistance to $\beta$-lactam antibiotics, MRSA may often demonstrate an increased resistance towards other groups of antibiotics. Our study on the influence of EEPP on MSSA and MRSA strains showed no significant differences, both MIC and MBC values obtained for these strains 
were relatively similar. This may lead to the conclusion that EEPP demonstrates an essential anti-staphylococcal activity not associated with beta-lactam antibiotics. Gonsales et al. observed the antibacterial activity of propolis using a diffusion method, in which EEP inhibited S. aureus growth, with diameters of the growth inhibition zones ranging from 8 to $13 \mathrm{~mm}$ [50]. Similar results were obtained by Stepanovic et al. In their study, the zone of microbial growth inhibition for 13 propolis samples obtained from different geographic regions of Serbia were in the range from 9 to $13 \mathrm{~mm}$ [43].

To estimate the combined effect of EEPP with a set of widely used antibiotics, the propolis in concentrations which did not by itself inhibit bacterial growth were used on solid MHA plates in the disk diffusion assay.

MIC is usually measured by the broth dilution method and the convenient disk diffusion method, however the convenient disk diffusion method-based analysis is also used frequently to estimate drug susceptibility. These methods, using visual evaluation of bacterial growth in the presence of a tested compound, do not take into the consideration the cell metabolism. Therefore, a special technique is required for the assessment of bactericidal activity.

In our study, the addition of EEPP at a concentration equal to $1 / 4$ of $\mathrm{MIC}_{90}(0.2 \mathrm{mg} / \mathrm{mL})$ to $\mathrm{MHA}$ medium significantly increased sensitivity of $S$. aureus strains to DA $(p=0.018)$, TET $(p=0.005)$, TOB $(p=0.033)$, LIN $(p=0.005)$, and SXT $(p=0.018)$. Such synergy between EEPP and antibiotics was also observed for FOX ( $p=0.067), \mathrm{E}(p=0.201)$ and $\mathrm{P}(p=0.173)$, but the values did not reach statistical significance. In particular, a strong combined effect was observed in the case of TET and SXT, for which diameters of the growth inhibition zones on MHA medium with addition of EEPP were larger by 11-12 $\mathrm{mm}$ that the measured on MHA medium without EEPP. For the remaining antibiotics (FOX, DA, CIP, TOB, LIN) tested in combination with EEPP, the diameters of the growth inhibition zones were larger by $4-8 \mathrm{~mm}$ than that measured on MHA medium without EEPP.

Synergistic effects of propolis and antibiotics on the growth of $S$. aureus have been reported previously by Krol et al. [34]. However, this effect was significant only at a propolis concentration of $0.6 \mathrm{mg} / \mathrm{mL}$, while in our experiment the effect appeared at $0.2 \mathrm{mg} / \mathrm{mL}$ EEPP concentration.

EEP is known to contain a number of antimicrobial compounds, such as polyphenols and flavonoids. The antimicrobial and resistance modifying potentials of natural compounds have been reported by Cushnie and Lamb [51]. This suggests that the synergy with antibiotics observed in this study could be attributed to such compounds. Some of these compounds, like polyphenols, have been shown to exert their antibacterial action through membrane perturbations. This perturbation of the cell membrane coupled with the action of $\beta$-lactams on the transpeptidation of the cell membrane could lead to the enhanced antimicrobial effect [52].

\section{Experimental}

\subsection{Ethanolic Extract of Polish Propolis (EEPP)}

Propolis samples produced by honeybees (Apis mellifera) from an apiary in Kamianna near Nowy Sacz in southern Poland constituted the material for the study. This area is primarily rich in black poplar (Populus nigra), birch (Betula alba), alder (Alnus glutinosa), beech (Fagus sylvatica) and horsechestnut (Aesculus hippocastanum). Hand collected propolis were kept desiccated in the dark 
prior to its processing. Propolis was subjected to 14 days of extraction in order to obtain the ethanol extract of propolis, which was later dissolved in $70 \%$ ethanol to obtain a $100 \mathrm{mg} / \mathrm{mL}$ working concentration. Briefly, the samples were ground mechanically and bottled in $10 \mathrm{~g}$ portions. The $10 \mathrm{~g}$ portions were put into flask and $100 \mathrm{~g}$ of $70 \%$ ethanol $(\mathrm{w} / \mathrm{v})$ was added. The flask was placed on a rotary shaker in a dark, closed room for two weeks in room temperature. After this period, the extract was cooled in $4{ }^{\circ} \mathrm{C}$ for $24 \mathrm{~h}$ in order to precipitate all insoluble particles, which were removed from the propolis extract by filtration through filter paper (Whatman no. 4). Next, the obtained filtrate was evaporated to dryness at $40{ }^{\circ} \mathrm{C}$ using a rotary vacuum evaporator. In order to prepare a working concentration, the brown colored viscous substance was dissolved in $70 \%$ ethanol.

\subsection{HPLC-DAD Analysis of EEPP}

To determine the chemical composition of EEPP a high performance liquid chromatography method was applied. Analysis was run on a Varian 920-LC HPLC (Harbor City, CA, USA), equipped with a 900-LC model autosampler, gradient pump, 330 model DAD, and the Galaxie software for data acquisition and processing. Separation was achieved using gradient mode on a Pursuit C18 (5 $\mu \mathrm{m}$ particle size $)$ column $(250 \times 4.6 \mathrm{~mm}$ id; Varian; Cat. no. 1215-9307) using water, formic acid (95:5, $\mathrm{v} / \mathrm{v}$ ) (solvent A) and acetonitrile (solvent B). The elution was carried out at a flow rate of $0.6 \mathrm{~mL} / \mathrm{min}$. The separations were performed with a gradient elution: $20 \%-30 \%$ solvent B (for 15 min), 30\% solvent B (15-28 min), 30\%-80\% solvent B (28-50 min), 80\% solvent B (50-54 min), $80 \%-40 \%$ solvent B (54-60 min) and 40\%-20\% solvent B (60-65 min) The detection was monitored at 254 and $340 \mathrm{~nm}$ and the components identified by comparison with standards acquired commercially or isolated during previous work. EEPP were filtered with a $0.22 \mu \mathrm{m}$ filter (Millipore) prior to injection of $20 \mu \mathrm{L}$ into the HPLC system. Standard mixtures in ethanol containing chrysin, apigenin, acacetin, galangin, kaempferol, kaempferid, quercetin, pinostrombin, gallic acid, ferulic acid, cinnanic acid, $o$-coumaric acid, $m$-coumaric acid, $p$-coumaric acid, caffeic acid and caffeic acid phenylethyl ester (CAPE) were prepared from standard stock solutions (each at a concentration of $0.1 \mathrm{mg} / \mathrm{mL}$ in ethanol). All phenolic compounds were purchased from Carl Roth GmbH (Karlsruhe, Germany) and Sigma Chemical Company (St. Louis, MO, USA).

\subsection{Bacterial Strains}

The antibacterial activity of EEPP was assessed against ten coagulase-positive $S$. aureus strains isolated from blood clinical samples, and two reference strains of S. aureus ATCC 25923 and S. aureus ATCC 43300 as the MSSA and MRSA positive controls, respectively. Isolates were identified by conventional methods, including Gram staining, colony morphology, hemolysis, test for catalase, coagulase activity and anaerobic fermentation of mannitol. Catalase positive and coagulase positive staphylococcal isolates were identified by the API STAPH system (bioMerieux, Marcy l'Etoile, France) according to the manufacturer's instructions. All bacterial strains were stored in Trypticase Soy Broth (TSB) medium with $20 \%$ of glycerol at $-86^{\circ} \mathrm{C}$, until further analyses were performed. 


\subsection{Molecular Identification of Isolated Strains-PCR-RFLP Analysis of dnaJ Gene}

For molecular analyses, bacterial genomic DNA was extracted with the GeneMATRIX Tissue \& Bacterial DNA Purification KIT (EuRx Ltd., Gdańsk, Poland) according to the manufacturer's recommendations and used for the PCR-RFLP analysis as described previously by Shah et al. [53]. Briefly, the dnaJ primers SA-(F) (5'-GCC AAA AGA GAC TAT TAT GA-3') and SA-(R) (5'-ATT GYT TAC CYG TTT GTG TAC C-3') were used to amplify the dnaJ gene fragment. The PCR amplification was performed using $10 \times$ PCR RED master mix kit (BLIRT SA, Poland) in a MJ Mini Personal Thermal Cycler (Bio-Rad, Hercules, CA, USA). The PCR products were visualized under UV light after the electrophoretic separation in a 1.5\% agarose gel (Promega, Madison, WI, USA) with ethidium bromide (EtBr). To identify isolated staphylococci strains, the PCR products were treated with $10 \mathrm{U}$ of the XapI or Bsp143I restriction enzymes to obtain the species-specific restriction profiles. Digestions were performed in a total volume of $15 \mu \mathrm{L}$, with $5 \mu \mathrm{L}$ of the PCR products, $1 \mu \mathrm{L}$ of reaction buffer and $10 \mathrm{U}$ of the XapI or Bsp143I endonucleases (Fermentas, Vilnius, Lithuania) for $3 \mathrm{~h}$ at $37{ }^{\circ} \mathrm{C}$ [54]. The obtained fragments were separated in a $2 \%$ agarose gel with EtBr (Promega), visualized under the UV light, and checked for size against $1 \mathrm{~Kb}$ HypeLadderIV (BLIRT SA, Gdańsk, Poland) molecular weight marker.

\subsection{MSSA and MRSA Detection}

\subsubsection{Cefoxitin Test}

MRSA isolates were detected using cefoxitin disk diffusion method. A colony suspension equivalent to 0.5 McFarland was inoculated to Mueller-Hinton agar (MHA-BTL, Łódź, Poland), with a $30 \mu \mathrm{g}$ cefoxitin disk (EMAPOL, Gdańsk, Poland) and interpreted after $20 \mathrm{~h}$ of incubation at $35{ }^{\circ} \mathrm{C}$. MRSA strains were identified using a breakpoint of $\leq 21 \mathrm{~mm}$ zone diameter size for cefoxitin disks.

\subsubsection{The mecA Gene Detection}

PCR detection of the mecA gene was performed with the primers and reaction conditions described previously by Murakami et al. [55]. MecA primers complementary to the penicillin binding protein (PBP2') coding region (F) (5'-AAA ATC GAT GGT AAA GGT TGG C-3') and (R) (5'-AGT TCT GCA GTA CCG GAT TTG C-3') were used. The PCR amplification was performed using $10 \times$ PCR RED master mix kit (BLIRT SA) in a MJ Mini Personal Thermal Cycler (Bio-Rad). The PCR products of 533 bp were detected under UV light after electrophoretic separation in a $1.5 \%$ agarose gel (Promega) with EtBr.

\subsection{Antibacterial Susceptibility Testing}

\subsubsection{Disk Diffusion Method}

All isolates were tested for antimicrobial susceptibility by the disk diffusion method-based analysis, using MHA and commercially available disks containing an antimicrobial agent according to the EUCAST recommendations [56]. For disk diffusion testing, $90 \mathrm{~mm}$ plates with the agar medium were 
inoculated by swabbing the agar with a swab soaked in a bacterial suspension of $1 \times 10^{8}$ cells $/ \mathrm{mL}$. Disks (EMAPOL) containing penicillin (P) $1 \mathrm{IU}$, erythromycin (E) $15 \mu \mathrm{g}$, clindamycin (DA) $2 \mu \mathrm{g}$, cefoxitin (FOX) $30 \mu \mathrm{g}$, ciprofloxacin (CIP) $5 \mu \mathrm{g}$, tobramycin (TOB) $10 \mu \mathrm{g}$, chloramphenicol (C) $30 \mu \mathrm{g}$, linezolid (LIN) $10 \mu \mathrm{g}$, tetracycline (TE) $30 \mu \mathrm{g}$ or trimethoprim+sulfamethoxazole (SXT) $1.25+23.75 \mu \mathrm{g}$ were used for the analysis of antimicrobial susceptibility.

The combined effect of antibiotics and EEPP was studied using plates with MHA plus one-fourth of MIC90 of EEPP, which was considered as a sub-inhibitory concentration [38,57]. Disks were placed onto agar surface and gently pressed to ensure contact using sterile forceps. Plates were incubated at $35{ }^{\circ} \mathrm{C}$ for $20 \mathrm{~h}$ in air. The susceptibility testing of each antibiotic for each isolate and the reference strains was performed in triplicates. After the incubation period diameters of the growth inhibition zones (in $\mathrm{mm}$ ) were measured for each strain, and the mean values were calculated.

\subsubsection{Microdilution Method}

MICs of EEPP were determined by the broth microdilution liquid and growth inhibition method. Growth inhibition assays were performed in the sterile Nunc 96-well plates, in a final volume of $200 \mu \mathrm{L}$ [58,59]. The cell concentrations were estimated from the optical densities at $600 \mathrm{~nm}$ wavelength with the formula $\mathrm{CFU} / \mathrm{mL}=A_{600}\left(3.8 \times 10^{8}\right)$, where $\mathrm{CFU}$ was the number of colony-forming units. One hundred microliters of mid-logarithmic-phase bacterial cultures $\left(5 \times 10^{5} \mathrm{CFU} / \mathrm{mL}\right)$ in Mueller-Hinton broth (MHB) was added to $100 \mu \mathrm{L}$ of serially diluted EEPP (12.5 to $0.01 \mathrm{mg} / \mathrm{mL}$ ). Wells containing MHB with bacterial inoculum only served as the bacterial growth control (GC). Additional controls included MHB alone (medium sterility control), MHB with different concentrations of EEPP, and MHB with different concentration of $70 \%$ ethanol and bacterial inoculum. All samples were prepared in triplicates. Microplates were incubated at $37{ }^{\circ} \mathrm{C}$ for $20 \mathrm{~h}$, and the bacterial cell growth was assessed by measuring the optical density of cultures at $600 \mathrm{~nm}$ wavelength with a Multiskan EX microplate reader (Thermo Electron Corp., Vantaa, Finland) [60,61].

The MICs were defined as the lowest concentration that completely inhibits bacterial growth $[58,59,61]$. The $\mathrm{MIC}_{50}$ represents the MIC value at which $\geq 50 \%$ of the isolates in a test population are inhibited and is equivalent to the median MIC value. The $\mathrm{MIC}_{90}$ represents the MIC value at which $\geq 90 \%$ of the strains within a test population are inhibited; the $90^{\text {th }}$ percentile [62].

The MBCs were expressed as the lowest concentration of an antimicrobial agent $(\mathrm{mg} / \mathrm{L})$, that in vitro reduces the number of bacteria by $99.9 \%$, within a defined period of time [56]. To determine the MBC value of EEPP $100 \mu \mathrm{L}$ aliquots from each EEPP dilution, were transferred into MHA plates and incubated at $37{ }^{\circ} \mathrm{C}$ for $20 \mathrm{~h}$. After incubation period, the number of colonies was calculated, and the initial CFU/well retrospectively determined [63].

\subsection{Statistical Analyses}

To determine the percentage of the variation attributable to the factors such as bacterial strains, time, and concentrations the results concerning the bacterial growth were analyzed by a three-way analysis of variance (ANOVA). The results from synergism assay were submitted to the Wilcoxon Signed-Rank Test comparing the values $(\mathrm{mm})$ of the inhibitory zone in the disk diffusion method. All 
statistical analyses were performed using the Statistica 10.0 PL software package, assuming the statistical significance level of $p<0.05$.

\section{Conclusions}

Our data showed that clinical strains of MSSA and MRSA with different drug resistance patterns were susceptible to EEPP. The action of EEPP was manifested by both growth inhibition of microorganisms (MIC) and bactericidal (MBC) activity. What is more, the observed synergistic effects of EEPP with commonly used antibiotics should induce further research on including EEPP in antimicrobial therapy schemes to augment their potential toward clinical strains of S. aureus.

Despite the fact, that the results presented in our study are promising, further randomized studies are needed to determine the clinical effectiveness of the synergistic action of propolis and antimicrobial drugs on staphylococci infections resistant to standard treatments. The propolis extract may facilitate and augment the antibiotic action by correcting the pharmacokinetic and pharmaco-dynamic properties and thus potentiate its biological action.

\section{Acknowledgments}

We would like to express our gratitude to the medical staff of participating hospitals within the Silesia region for the bacterial strain collection.

This study was supported by the research grant from Medical University of Silesia no. KNW $1-003 / \mathrm{N} / 3 / 0$.

\section{Conflict of Interest}

The authors declare no conflict of interest.

\section{References}

1. Gordon, J.R.; Lowy, F.D. Pathogenesis of methicillin-resistant Staphylococcus aureus infection. Clin. Infect. Dis. 2008, 46, 350-359.

2. Casey, A.L.; Lambert, P.A.; Elliott, T.S.J. Staphylococci. Int. J. Antimicrobial. Agents 2007, $29,23-32$.

3. Ippolito, G.; Leone, S.; Lauria, F.N.; Nicastri, E.; Wenzel, R.P. Methicillin-resistant Staphylococcus aureus: The superbug. Int. J. Infect. Dis. 2010, 14, 7-11.

4. Wertheim, H.F.; Melles, D.C.; Vos M.C.; van Leeuwen W.; van Belcum A.; Verbrugh H.A.; Nouwen J.C. The role of nasal carriage in Staphylococcus aureus infections. Lancet Infect. Dis. 2005, 5, 751-762.

5. Liu, G.Y. Molecular Pathogenesis of Staphylococcus aureus Infection. Pediatric Res. 2009, 65, 71-77.

6. Bächi, B.B.; Rohrer, S. Factors influencing methicillin resistance in Staphylococci. Arch. Microbiol. 2002, 178, 165-171. 
7. Cosgrove, S.E.; Qi, Y.; Kaye K.S.; Harbarth, S.; Karchmer, A.W.; Carmeli, Y. The impact of methicillin resistance in Staphylococcus aureus bacteremia on patient outcomes: mortality, length of stay, and hospital charges. Infect. Control. Hosp. Epidemiol. 2005, 26, 166-174.

8. Bankova, V. Recent trends and important developments in propolis research. Evid. Based Comp. Alter. Med. 2005, 2, 29-32.

9. Castaldo, S.; Capasso, F. Propolis, an old remedy used in modern medicine. Fitoterapia 2002, $73,1-6$.

10. Paulino, N.; Teixeira, C.; Martins, R.; Scremin, A.; Dirsch, V.M.; Vollmar, A.M.; Abreu, S.R.; de Castro, S.L.; Marcucci, M.C. Evaluation of the analgesic and antiinflammatory effects of a Brazilian green propolis. Planta Med. 2006, 72, 899-906.

11. Borrelli, F.; Maffia, P.; Pinto, L.; Ianaro, A.; Russo, A.; Capasso, F.; Ialenti, A. Phytochemical compounds involved in the anti-inflammatory effect of propolis extract. Fitoterapia 2002, 73, 53-63.

12. Orsatti, C.L.; Missima, F.; Pagliarone, A.C.; Bachiega, T.F.; Búfalo, M.C.; Araújo Jr, J.P.; Sforcin, J.M. Propolis immunomodulatory action in vivo on Toll-like receptors 2 and 4 expression and on pro-inflammatory cytokines production in mice. Phytother. Res. 2010, 24, 1141-1146.

13. Orsolić, N.; Knezević, A.H.; Sver, L.; Terzić, S.; Basić, I. Immunomodulatory and antimetastatic action of propolis and related polyphenolic compounds. J. Ethnopharmacol. 2004, 94, 307-315.

14. Búfalo, M.C.; Candeias, J.M.; Sforcin, J.M. In vitro cytotoxic effect of Brazilian green propolis on human laryngeal epidermoid carcinoma (HEp-2) cells. Evid. Based Comp. Alter. Med. 2009, 6, 483-487.

15. Szliszka, E.; Czuba, Z.P.; Bronikowska, J.; Mertas, A.; Paradysz, A.; Krol, W. Ethanolic extract of propolis (EEP) augments TRAIL-induced apoptotic death in prostate cancer cells. Evid. Based Comp. Alter. Med. 2011, Article ID 535172.

16. Nakajima, Y.; Shimazawa, M.; Mishima, S.; Hara, H. Water extract of propolis and its main constituents, caffeoylquinic acid derivatives, exert neuroprotective effects via antioxidant actions. Life Sci. 2007, 80, 370-377.

17. Teixeira, E.W.; Message, D.; Negri, G.; Salatino, A.; Stringheta, P.C. Seasonal variation, chemical composition and antioxidant activity of Brazilian propolis samples. Evid. Based Comp. Alter. Med. 2010, 7, 307-315.

18. Montoro, A.; Almonacid, M.; Serrano, J.; Saiz, M.; Barquinero, J.F.; Barrios, L.; Verdu, G.; Perez, J.; Villaesusa, J.I. Assessment by cytogenetic analysis of the radioprotection properties of propolis extract. Radiat. Prot. Dosimetry 2005, 115, 461-464.

19. Kujumgiev, A.; Tsvetkova, I.; Serkedjieva, Y.; Bankova, V.; Chistov, R.; Popov, S. Antibacterial, antifungal and antiviral activity of propolis of different geographic origin. J. Ethnopharmacol. 1999, 64, 235-240.

20. Silici, S.; Koç, N.A.; Ayangil, D.; Cankaya, S. Antifungal activities of propolis collected by different races of honeybees against yeasts isolated from patients with superficial mycoses. J. Pharmacol. Sci. 2005, 99, 39-44.

21. Kayaoglu, G.; Ömürlü, H.; Akca, G.; Gürel, M.; Gençay, Ö.; Sorkun, K.; Salih, B. Antibacterial activity of Propolis versus conventional endodontic disinfectants against Enterococcus faecalis in infected dentinal tubules, J. Endodont. 2011, 37, 376-381. 
22. Lu, L.C.; Chen, Y.W.; Chou, C.C. Antibacterial activity of propolis against Staphylococcus aureusInt. J. Food Endodont. 2005, 102, 213-220.

23. Stojko, J.; Wojtyczka, R.D.; Kabała-Dzik, A.; Stojko, R.; Kępa M.; Moździerz, A. Comparative studies on the antimicrobial activity of apitherapeutics applied to experimental burn wounds. Pol. J. Environ. Stud. 2007, 16, 612-615.

24. Silici, S.; Kutluca, S. Chemical composition and antibacterial activity of propolis collected by three different races of honeybees in the same region. J. Ethnopharmacol. 2005, 99, 69-73.

25. Wojtyczka, R.D.; Kępa, M.; Idzik, D.; Kubina, R.; Kabała-Dzik, A.; Dziedzic, A.; Wąsik, T.J. In vitro Antimicrobial Activity of Ethanolic Extract of Polish Propolis Against Biofilm Forming Staphylococcus epidermidis Strains. Evid. Based Comp. Alter. Med. 2013, 590703.

26. Seidel, V.; Peyfoon, E.; Watson, D.G.; Fearnley, J. Comparative study of the antibacterial activity of propolis from different geographical and climatic zones. Phytother. Res. 2008, 22, 1256-1263.

27. Trusheva, B.; Popova, M.; Bankova V.; Simova S.; Marcucci M.C.; Miorin P.L.; da Rocha Pasin F.; Tsvetkova I. Bioactive constituents of Brazilian propolis. Evid. Based Comp. Alter. Med. 2006, 3 , 249-254.

28. Mirzoeva, O.K.; Grishanin, R.N.; Calder, P.C. Antimicrobial action of propolis and some of its components: the effects on growth, membrane potential and motility of bacteria. Microbiol. Res. 1997, 152, 239-246.

29. Takaisi-Kikuni, N.B.; Schilcher, H. Electron microscopic and microcalorimetric investigations of the possible mechanism of the antibacterial action of a defined propolis provenance. Planta Med. 1994, 60, 222-227.

30. Theuretzbacher, U. Accelerating resistance, inadequate antibacterial drug pipelines and international responses. Int. J. Antimicrob. Agents 2012, 39, 295-299.

31. Sha, N.; Huang, H.L.; Zhang, J.Q.; Chen, G.T.; Tao, S.J.; Yang, M.; Li, X.N.; Li, P.; Guo, D.A. Simultaneous quantification of eight major bioactive phenolic compounds in Chinese propolis by high-performance liquid chromatography. Nat. Prod. Commun. 2009, 4, 813-818.

32. Popova, M.; Chen, C.N.; Chen, P.Y.; Huang, C.Y.; Bankova, V. A validated spectrophotometric method for quantification of prenylated flavanones in pacific propolis from Taiwan. Phytochem. Anal. 2010, 21, 186-191.

33. Chang, R.; Piló-Veloso, D.; Morais, S.A.; Nascimento, E.A. Analysis of a Brazilian green propolis from Baccharis dracunculifolia by HPLC-APCI-MS and GC-MS. Braz. J. Pharmacognosy 2008, 18, 549-56.

34. Krol, W.; Scheller, S.; Shani, J.; Pietsz, G.; Czuba, Z. Synergistic effect of ethanolic extract of propolis and antibiotics on the growth of Staphylococcus aureus. Arzneimittelforschung 1993, 43, 607-609.

35. Orsi, R.O.; Fernandes Junior, A.; Bankova, V.; Sforcin, J.M. Antibacterial effects of Brazilian and Bulgarian propolis and synergistic effects with antibiotics acting on the bacterial DNA and folic acid. Nat. Prod. Res. 2012, 26, 344-349.

36. Havsteem, B. Flavonoids, a class of natural products of high pharmacology potency. Biochem. Pharmacol. 1983, 32, 1141-1148.

37. Oksuz, H.; Duran, N.; Tamer, C.; Cetin, M.; Silici, S. Effect of propolis in the treatment of experimental Staphylococcus aureus keratitis in rabbits. Ophthalmic Res. 2005, 37, 328-334. 
38. Fernandes Junior, A.; Balestrin, E.C.; Betoni, J.E.C.; Orsi, R.O.; da Cunha, M.R.S.; Montelli, A.C. Propolis: anti-Staphylococcus aureus activity and synergism with antimicrobial drugs. Mem. Inst. Oswaldo Cruz. 2005, 100, 563-566.

39. Nostro, A.; Cellini, L.; di Bartolomeo S.; Cannatelli, M.A.; di Campli, E.; Procopio, F.; Grande, R.; Marzio, L.; Alonzo, V. Effects of combining extracts (from propolis or Zingiber officinale) with clarithromycin on Helicobacter pylori. Phytother. Res. 2006, 20, 187-190.

40. Orsi, R.O.; Sforcin, J.M.; Funari, S.R.C.; Fernandes Junior, A.; Bankova, V. Synergistic effect of propolis and antibiotics on the Salmonella typhi. Braz. J. Microbiol. 2006, 37, 108-112.

41. Orsi, R.O.; Fernandes, A.; Bankova, V.; Sforcin, J.M. The effects of Brazilian and Bulgarian propolis in vitro against Salmonella Typhi and their synergism with antibiotics acting on the ribosome. Nat. Prod. Res. 2012, 26, 430-437.

42. Speciale, A.; Costanzo, R.; Puglisi, S.; Musumeci, R.; Catania, M.R.; Caccamo, F.; Iauk, L. Antibacterial activity of propolis and its active principles alone and in combination with macrolides, beta-lactams and fluoroquinolones against microorganisms responsible for respiratory infections. J. Chemother. 2006, 18, 164-171.

43. Stepanovic, S.; Antic, N.; Dakic, I.; Svabic-Vlahovic, M. In vitro antimicrobial activity of propolis and synergism between propolis and antimicrobial drugs. Microbiol. Res. 2003, 158, 353-357.

44. Boucher, H.W.; Corey, G.R. Epidemiology of methicillin-resistant Staphylococcus aureus. Clin. Infect. Dis. 2008, 46, 344-349.

45. Dziedzic, A.; Kubina, R.; Wojtyczka, R.D.; Kabała-Dzik, A.; Tanasiewicz, M.; Morawiec, T. The Antibacterial Effect of Ethanol Extract of Polish Propolis on Mutans Steptococci and Lactobacilli Isolated from Saliva. Evid. Based Comp. Alter. Med. 2013, 681891.

46. Kabała-Dzik, A.; Szaflarska-Stojko, E.; Wojtyczka, R.D.; Stojko, A.; Stojko, R.; Pacha, J. Comparative studies on the antimicrobial activity of propolis balm and silver sulphadiazine applied to burn wounds in pigs. Bull. Vet. Inst. Pulawy 2003, 47, 541-545.

47. Morawiec, T.; Dziedzic, A.; Niedzielska, I.; Mertas, A.; Tanasiewicz, M.; Skaba, D.; Kasperski, J.; Machorowska-Pieniążek, A.; Kucharzewski, M.; Szaniawska K.; et al. The biological activity of propolis-containing toothpaste on oral health environment in patients who underwent implant-supported prosthodontic rehabilitation. Evid. Based Comp. Alter. Med. 2013, 2013, 704947.

48. Kilic, A.; Baysallar, M.; Besirbellioglu, B.; Salih, B.; Sorkun, K.; Tanyuksel, M. In vitro antimicrobial activity of propolis against methicillin-resistant Staphylococcus aureus and vancomycin-resistant Enterococcus faecium. Ann. Microbiol. 2005, 55, 113-117.

49. Berretta, A.A.; Nascimento, A.P.; Bueno, P.C.; de Oliveira Lima Leite Vaz, M.M.; Marchetti, J.M. Propolis standardized extract (EPP-AF®), an innovative chemically and biologically reproducible pharmaceutical compound for treating wounds. Int. J. Biol. Sci. 2012, 8, 512-521.

50. Gonsales, G.Z.; Orsi, R.O.; Fernandes Junior, A.; Rodrigues, P.; Funari, S.R.C. Antibacterial activity of propolis collected in different regions of Brazil. J. Venom. Anim. Toxins Incl. Trop. Dis. 2006, 12, 276-284.

51. Cushine, C.O.; Lamb, A.J. Antimicrobial activity of flavonoids. Int. J. Antimicrob. Agents 2005, $26,343-356$. 
52. Esimone, C.O.; Iroha, I.R.; Ibezim, E.C.; Okeh, C.O.; Okpana, E.M. In vitro evaluation of the interaction between tea extracts and penicillin G against Staphylococcus aureus. Afr. J. Biotechnol. 2006, 5, 1082-1086.

53. Shah, M.M.; Iihara, H.; Noda, M.; Song, S.X.; Nhung, P.H.; Ohkusu, K.; Kawamaura, Y.; Ezaki, T. dnaJ gene sequence-based assay for species identification and phylogenetic grouping in the genus Staphylococcus. Int. J. Syst. Evol. Microbiol. 2007, 57, 25-30.

54. Hauschild, T.; Stepanovic, S. Identification of Staphylococcus spp. by PCR-restriction fragment length polymorphism analysis of dnaJ gene. J. Clin. Microbiol. 2008, 46, 3875-3879.

55. Murakami, K.; Minamide, W.; Wada, K.; Nakamura, E.; Teraoka, H.; Watanabe, S. Identification of methicillin-resistant strains of Staphylococci by polymerase chain reaction. J. Clin. Microbiol. 1991, 29, 2240-2244.

56. European Committee for Antimicrobial Susceptibility Testing (EUCAST) of the European Society of Clinical Microbiology and Infectious Diseases (ESCMID). Terminology relating to methods for the determination of susceptibility of bacteria to antimicrobial agents. EUCAST definitive document E. Def 1.2. Clin. Microbiol. Infect. 2000, 6, 503-508.

57. Mahon, C.R.; Manuselis, J.R.G. Textbook of Diagnostic Microbiology; Publisher: WB Saunders, Philadelphia, PA, USA, 1995; p. 1134.

58. Amsterdam, D. Susceptibility Testing of Antimicrobials in Liquid Media. In Antibiotics in Laboratory Medicine, 5th ed.; Loman, V., Ed; Williams and Wilkins: Philadelphia, PA, USA, 2005; pp. 61-143.

59. European Committee for Antimicrobial Susceptibility Testing (EUCAST) of the European Society of Clinical Microbiology and Infectious Diseases (ESCMID). Determination of minimum inhibitory concentrations (MICs) of antibacterial agents by broth dilution. EUCAST discussion document E.dis. 5.1. Clin. Microbiol. Infect. 2003, 9, 1-7.

60. Cudic, M.; Condie, B.A.; Weiner D.J.; Lysenko, E.S.; Xiang, Z.Q.; Insug, O.; Bulet, P.; Otvos, L., Jr. Development of novel antibacterial peptides that kill resistant clinical isolates. Peptides 2002, 23, 2071-2083.

61. Devienne, K.F.; Raddi, M.S.G. Screening for antimicrobial activity of natural Products using a microplate photometer. Braz. J. Microbiol. 2002, 33, 166-168.

62. Schwarz, S.; Silley, P.; Simjee, S.; Woodford, N.; van Duijkeren, E.; Johnson, A.P.; Gaastra, W. Editorial: Assessing the antimicrobial susceptibility of bacteria obtained from animals. J. Antimicrob. Chemother. 2010, 65, 601-604.

63. Bär, W.; Bäde-Schumann, U.; Krebs, A.; Cromme, L. Rapid method for detection of minimal bactericidal concentration of antibiotics. J. Microbiol. Methods. 2009, 77, 85-89.

Sample Availability: Samples of the compounds are available from the authors.

(C) 2013 by the authors; licensee MDPI, Basel, Switzerland. This article is an open access article distributed under the terms and conditions of the Creative Commons Attribution license (http://creativecommons.org/licenses/by/3.0/). 